\title{
Sizing of a Photovoltaic Installation for the Needs of an International Airport: Case Study of GNASSINGBE EYADEMA International Airport (AIGE)
}

\author{
Koffi Sagna $^{1,2, *}$, Yendoubé Lare ${ }^{1,2}$, Yendoubouame Lare ${ }^{1}$, Kossi Napo ${ }^{1,2}$ \\ ${ }^{1}$ Laboratory on Solar Energy, Department of Physics, Faculty of Sciences, University of Lomé, Lomé, Togo \\ ${ }^{2}$ Centre d'Excellence Régional Pour la Maîtrise de l'Electricité (CERME), University of Lomé, Lomé, Togo
}

Email address:

sakobeni@gmail.com (K. Sagna),ksagna@univ-lome.tg (K. Sagna)

${ }^{*}$ Corresponding author

To cite this article:

Koffi Sagna, Yendoubé Lare, Yendoubouame Lare, Kossi Napo. Sizing of a Photovoltaic Installation for the Needs of an International Airport: Case Study of GNASSINGBE EYADEMA International Airport (AIGE). International Journal of Sustainable and Green Energy. Vol. 10, No. 3, 2021, pp. 99-107. doi: 10.11648/j.ijrse.20211003.13

Received: September 1, 2021; Accepted: September 23, 2021; Published: October 2, 2021

\begin{abstract}
This paper presents the sizing of a photovoltaic (PV) system for the GNASSINGBE EYADEMA international airport. Technical and economic profitability studies were done in order to show the possibility and the relevance of using a PV installation to fully meet the energy needs of a large airport in a certain and profitable way, thus contributing to encourage airports to go for this form of energy in the perspective to reduce their environmental effects. In view of the load profile and because of operating constraints, it was proposed to design a grid-connected photovoltaic systems in self-consumption. Mathematical formulas and PVsyst software were used for the sizing. The results obtained showed that the sizing system has a peak power of $1 \mathrm{MWp}$. The total investment cost of the project was estimated at $\$ 2,100,000$. To evaluate the profitability of the project, the analysis was made according to two cases first if the project is financed with own funds and second if it is financed through a bank loan. It appeared that for funding own, the return on investment time is shorter, unlike when resorting to a bank. In addition, this PV power plant project would help to avoid 401.3 tonnes of $\mathrm{CO}_{2} /$ year.
\end{abstract}

Keywords: Photovoltaic System, Airport Energy Needs, Self-consumption, Economic Profitability

\section{Introduction}

The model of energy production in the world since the industrial revolution, based on fossil resources, has led to the problems of environmental pollution and climate change. It therefore appears essential to change the paradigm and favor less damaging production methods, especially for intensive energy consumption activities. Among intensive energy consumption activities, we can mention aviation industry. In fact, aviation consumes around $32 \%$ of electrical and thermal energy [1]. In addition to the consumption of aircrafts which represents the largest part, the supply of energy to airports entails a significant cost, especially in terms of electrical energy and constitutes a real challenge to be taken up because it is strictly prohibited to have a total "shut down" in an airport. Because of their energy consumption Airports are criticized for environmental pollution. Indeed, according to the International Civil Aviation Organization (ICAO), airports generate more than $0.1 \%$ of total $\mathrm{CO}_{2}$ emissions [2] These emissions come from a number of sources, including heating or power generation installations, emergency generators and incinerators, as well as fires set for training rescue teams and firefighters [3].

In addition to environmental pollution, the supply of energy to airports involves a significant economic cost and constitutes a challenge. It has been estimated that energy costs account for about five per cent of the operating costs of a modern airport [3]. To overcome this, it would be necessary that the civil aviation industry endeavors to control harmful environmental impacts. To meet these energy and environmental challenges, several solutions can be implemented. Regarding energy, the measures include modernization of equipment, optimization of energy efficiency of operations and buildings, use of renewable 
energies [4]. In terms of renewable energies, airports are moving towards solar energy. In Cameroon for example, Douala airport built a photovoltaic solar power plant intended to produce more than 1.2 MWp [5]. Chennai Airport in India uses $90 \%$ of the solar electricity it produces [2]. In Togo, despite the existence of a large potential of solar energy [6], airports have not yet taken this step. The main airport of the country, Gnassingbé Eyadéma international airport in Lomé (AIGE) consumes on average more than $540,000 \mathrm{kWh}$ per month for its operation, from the public grid. In order to offer an alternative solution, a technical and economic feasibility study project for the use of photovoltaic solar generators in self-consumption (without injection) is conducted. This paper presents the essence of the study.

\section{Methodological Approaches}

The purpose of sizing a solar photovoltaic system is to determine the energy of the photovoltaic generator from weather, climate data and the user's electrical energy needs. To achieve this, we have adopted the following methodological approach:

1) study geographic and weather conditions,

2) determine the energy needs of the airport,

3) size the PV system (modules, inverters, cables, etc.) using the PV system software and calculation methods based on standards,

4) analyze the economic and environmental viability.

5) PVsyst, Software for sizing photovoltaic systems, version 6.8.6,

6) Excel for data analysis.

\section{Geographical Conditions and Weather}

Meteorological conditions, particularly solar irradiation and temperature of the module influence the performance of a photovoltaic generator $[7,8]$. Also corrosion from moisture can degrade solar module and make it inefficient. In addition to these conditions, attention should be paid to local wind conditions when setting up the field. In fact, in strong winds, and depending on the orientation of the solar modules, the system may suffer material damage that could affect production.

The purpose of this part is to assess the various meteorological constraints that may have an impact on the choice of materials for the photovoltaic power plant, and which must be taken into account in the building and operation phases. The data used for this assessment were collected from the "Direction générale de la météorologie nationale (DGMN)" located in the airport area.

\subsection{Geographical Location}

The geographic coordinates of the site of the project are $6^{\circ} 10^{\prime} 11.69^{\prime \prime} \mathrm{N} ; 001^{\circ} 15^{\prime} 13.25^{\prime \prime} \mathrm{E}$.

\subsection{Sunstroke}

Figure 1 shows a diagram of the average monthly sunstroke hours in the airport area.

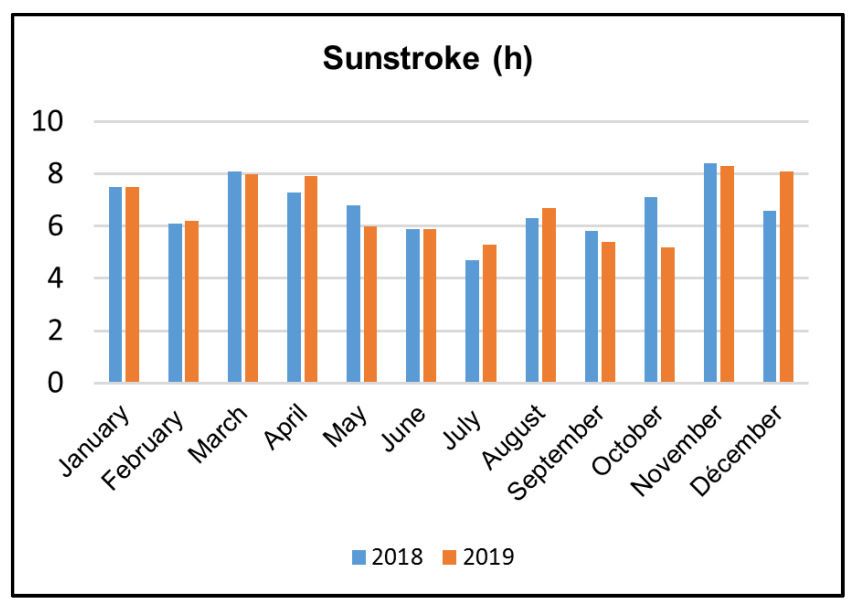

Figure 1. Diagram of sunstroke.

It can be observed that the sunniest months are from November to April and the least sunny months are from June to September.

\subsection{Relative Humidity}

Figure 2 presents the average, maximum and minimum relative humidity of site for 2018 .

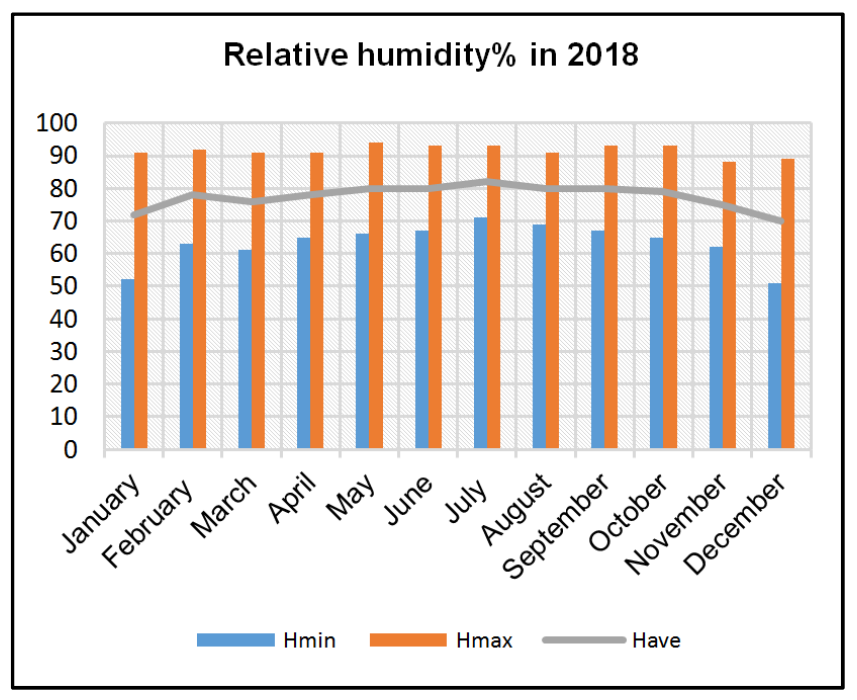

Figure 2. Relative humidity diagram in 2018.

It is shown that there are two (02) different periods in terms of relative humidity: a wet period from May to October where the average value exceeds $80 \%$ and a dry period from November to April where the average is less than $80 \%$. In this regard, it is important to prevent modules from corrosion due to moisture, so the edges of the modules must be anodized aluminum alloy.

\subsection{Temperature}

Annual and monthly average, maximum and minimum temperature data for the airport area are shown respectively in figures 3 and 4. 


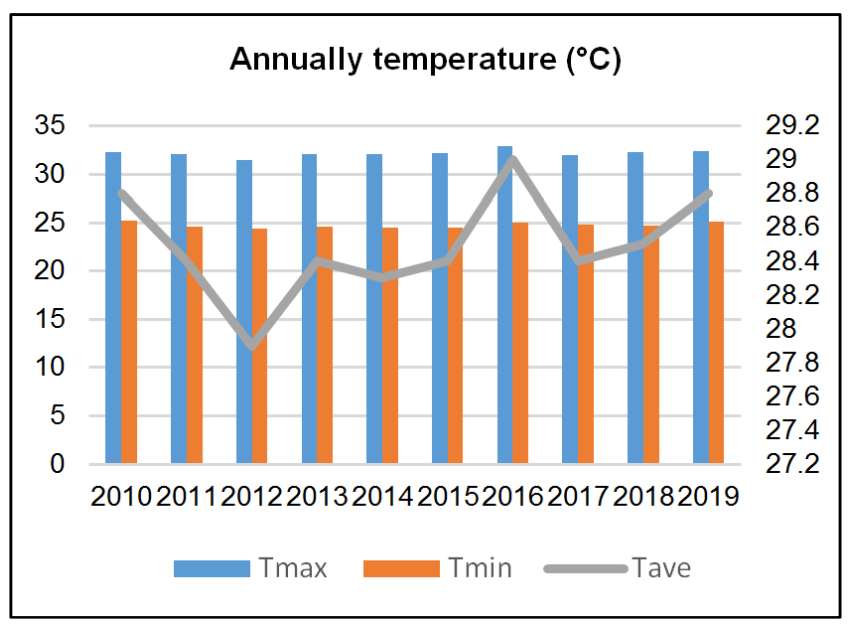

Figure 3. Annually temperature diagram.

From figure 3 it can be seen that the temperature variation are constant. The average annual temperature is $28^{\circ} \mathrm{C}$. The maximum and minimum temperatures observed are respectively $32^{\circ} \mathrm{C}$ and $25^{\circ} \mathrm{C}$.

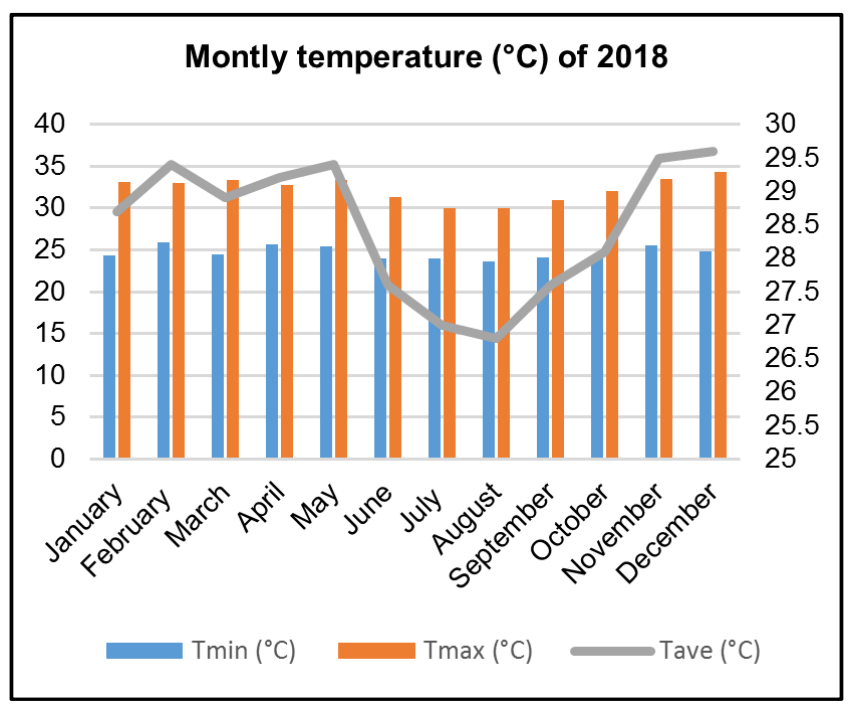

Figure 4. Monthly temperature diagram 2018.

According to figure 4, there are no significant temperature differences between the months of the year.

We observe two (02) different temperature periods: a slightly cooler period from June to September and a warmer one from November to April. These periods are in line with the wet and dry periods discussed above.

\subsection{Wind Speed and Direction}

The wind data of the last 10 years of the airport site are illustrated in figures 5 and 6.

Figures 5 and 6 show the wind diagram and the compass rose, respectively. It can be deduced that the dominant wind direction is southwest. According to history (not shown here), the maximum wind speed recorded at the airport site was 32 $\mathrm{m} / \mathrm{s}$ or $115 \mathrm{Km} / \mathrm{h}$ in 1956 . Given the prevailing wind direction, facilities must be oriented to the south to reduce damage in case of strong wind.

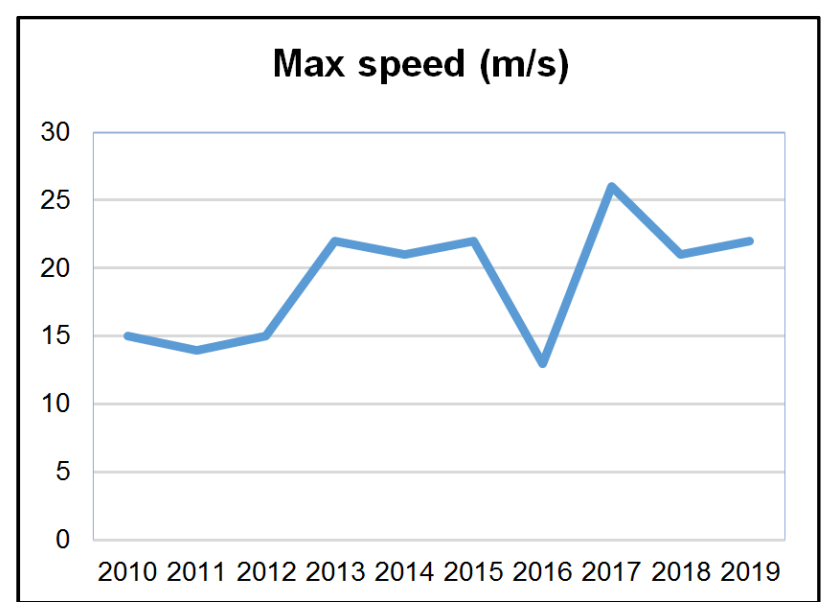

Figure 5. Wind diagram.

\section{Compass rose LOME}

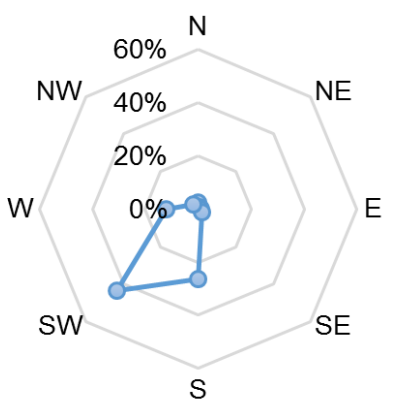

Figure 6. Compass rose of Lome.

\subsection{Solar Irradiation}

The global radiation of the site for the year 2019 is represented on figure 7 .

\section{9: Global radiation $\left(\mathrm{KWh} / \mathrm{m}^{2} / \mathrm{day}\right)$}

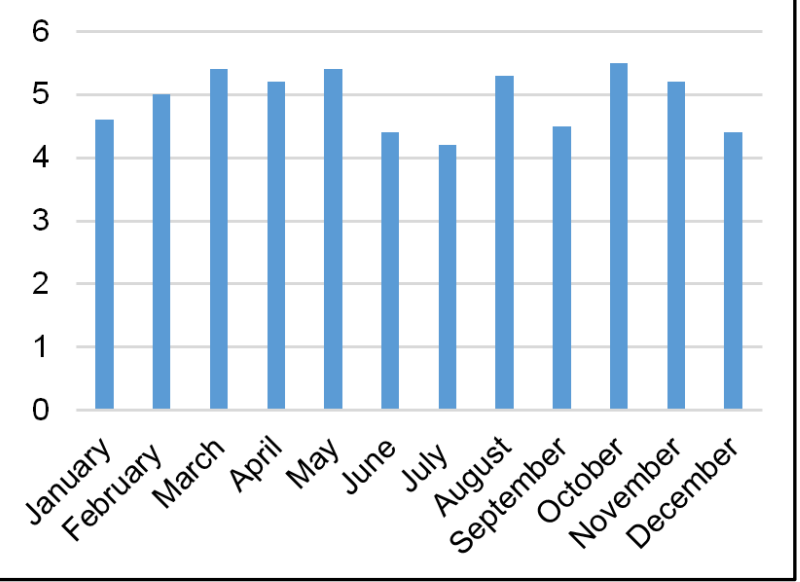

Figure 7. Global radiation diagram. 
It is noticed that the most unfavorable month in terms of solar radiation is July with a value of $4.2 \mathrm{KWh} / \mathrm{m}^{2}$.day.

\section{Energy Needs}

\subsection{Inventory of the Power Supply}

The analysis performed on the power grid of the airport's electricity supply highlights the use of two energy sources: a primary source from the public grid and an autonomous from generators set. In fact, the technical installations are supplied with back-up mode by automatic start-up generators in the event of failure of the public grid.

\subsection{Consumption}

The daily load profile of the airport (figure 8) shows a high daytime loads related to peak operation of all equipment due to airport traffic occurring during the day. This type of profile is ideal for a self-consumption photovoltaic solar installation.

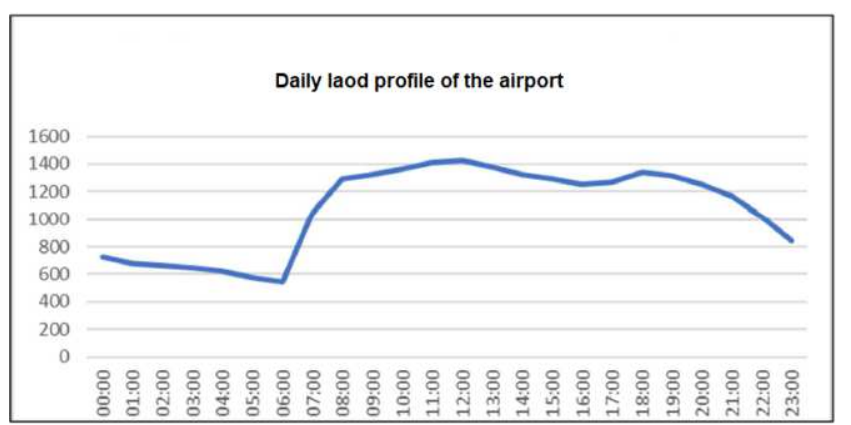

Figure 8. Daily load profile of the airport (source SALT).

According to this daily load profile, one MWp plant will be sufficient to cover the daily energy needs of the airport.

\section{Sizing of the PV System}

For grid-connected systems, the configuration of the PV solar field depends on the type of photovoltaic modules chosen and the characteristics of the inverter. Modules interconnected in a serial or parallel array compose the solar field. The configuration array depends on DC voltage required; the inverter imposes this [9].

\subsection{Inverter}

The main function of an inverter is to convert the DC voltage obtained from the solar generator into an $\mathrm{AC}$ current [9]. Since the inverter is connected to the grid, the standards given by the utility companies must be obeyed [10]. In fact, the current introduced should have a sinusoidal waveform and synchronized with the grid frequency and, in the event that the cutoff power failure, even for short periods, the inverter should be able to disconnect quickly. The grid inverters require the presence of the reference voltage of the primary power source, without this voltage, they cannot inject energy. The grid-connected inverter must be designed for the peak power and must obey conditions that deal with issues like power quality, detection of islanding operation, grounding, Maximum Power Point Tracking (MPPT) and long-life [9]. For optimal operation and best production, we have adopted the following design rules:

1) the voltage of the maximum power point (MPP) of the PV generator must be greater than the minimum voltage allowed at the input of the inverter,

2) the open-circuit voltage of the PV generator must be less than the maximum voltage allowed at the input of the inverter,

3) the strings connected to the same inverter must have the same direct voltage.

\subsection{Determination of the Total Number of Modules}

To find out the number of modules, we divide the power of the field to be installed by the power of the module. The number of modules thus required will be given by (1), (2) and (3):

$$
\begin{aligned}
& \text { Total number of modules } \leq \frac{P_{c \min }}{P_{\bmod }} \\
& \frac{U_{\_} \text {min MPP inverter }}{U_{\text {_MPP module }}}<\text { Number of modules in series }< \\
& \frac{\text { U_max MPP inverter }}{\text { U }_{\text {MPP module }}} \\
& \frac{\text { I_min MPP inverter }}{\text { I_MPP module }}<\text { Number of modules in parallel }< \\
& \frac{\text { I_max MPP inverter }}{\text { I_MPP module }}
\end{aligned}
$$

With $P_{\text {cmin }}$ minimum power of the plant and $P_{\text {mod }}$ power of the module; I_min MPP inverter , I_max MPP inverter , respectively minimum and maximum current of the maximum power point of the inverter; I MPP module: current of the maximum power point of the module; $\mathrm{U}_{\text {_min MPP inverter, }} \mathrm{U}_{\text {_max MPP inverter, }}$, respectively minimum and maximum voltage of the maximum power point of the

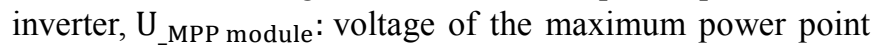
of the module.

\subsection{Cable Sizing}

The principles applied cables sizing, are the rules for the protection against electric shock, protection against thermal effects, protection against overcurrent.

\subsubsection{PV Module Protection Device}

\section{(i). String Protection Device}

The sizing of the plant protections is carried out taking into account the standards solar sector [11]. When several strings (at least 3) are connected in parallel, it is necessary to protect the conductors against overcurrents (reverse currents that can arise in faulty strings) using protection devices. In fact, a device for protecting the strings against overcurrents is required only if the number of strings of the generator $N_{c}$ is greater than maximum number of strings in parallel without protection $\left(N_{c \_ \text {max }}\right)$. The following relation (4) gives this $N_{c \_ \text {max }}$ : 


$$
N_{C_{-} \max } \leq 1+\frac{I_{R M}}{I_{S C_{S T C}}}
$$

With $I_{R M}$ reverse current of the module (information provided by the module manufacturer) and $I_{S C_{S T C}}$ the shortcircuit current of the module or string.

The maximum number of string in parallel $N_{p_{-} \max }$ that can be connected to a protection device is given by (5) [11]:

$$
N_{p_{-} \text {max }} \leq \frac{1+\frac{I_{R M}}{I_{S C_{S T C}}}}{2,4}
$$

If one string protection device is required, the nominal current $\left(I_{n}\right)$ to be assigned to the protection device is given by (6):

$$
1,4 * I_{S C_{-} S T C} \leq I_{n} \leq I_{R M}
$$

In the case of many strings, the $I_{n}$ to assign to string protection device is given by (7):

$$
1,4 * N_{p} * I_{S C_{-} S T C} \leq I_{n} \leq I_{R M}-\left(N_{p}-1\right) * I_{S C_{S T C}}
$$

The operating voltage $\left(\mathrm{U}_{\mathrm{e}}\right)$ of a protection device (fuse) is given by (8):

$$
\mathrm{U}_{\mathrm{e}} \geq 1,15 * \mathrm{U}_{\mathrm{oc}} * \mathrm{~N}_{\mathrm{s}}
$$

With: $\mathrm{U}_{\mathrm{oc}}$ open-circuit voltage and $\mathrm{N}_{\mathrm{s}}$ number of module in the string.

\section{(ii). Group Protection Device}

In case of several PV groups in parallel, the group cables must be protected against the effect of reverse currents due to a short circuit in a group. If PV groups are two in parallel, the maximum reverse current flowing in the cable of the faulty group can be up to $1,25 * I_{\text {SCSTC_Group }}$.

If the PV groups in parallel are $N_{a}>2$, the maximum reverse current flowing in the cable of the faulty group can be up to $(\mathrm{Na}-1) 1,25 I_{\text {ScSTC_Group }}$.

The nominal current (In) to be assigned to the PV group devices is given by (9):

$$
1,25 * I_{S C_{S T C_{-} \text {Group }}} \leq I_{n}
$$

Moreover, the operating voltage $\left(\mathrm{U}_{\mathrm{e}}\right)$ of a protection device (fuse) is given by (10):

$$
U_{e} \geq 1,15 * U_{o c} * N_{s}
$$

With: $\mathrm{U}_{\mathrm{oc}}$ open-circuit voltage and $\mathrm{N}_{\mathrm{s}}$ number of module in the string.

\section{(iii). Protection Against Atmospheric Overvoltage}

DC surge arresters provide the protection of photovoltaic installations against overvoltage of atmospheric origin.

\subsubsection{Chain Cables}

For the admissible current $\mathrm{I}_{\mathrm{z}}$ cables, we will assume that:

1) ambient temperature is $70^{\circ} \mathrm{C}$, and that the correction factor is $\mathrm{K}_{1}=0.58$;

2) cables are insulated in conduits or in ventilated channels;

3 ) configuration laying is Insulated conductors in single or multi-conductor conduits or cables in closed channels, horizontally or vertically, the correction factor is $\mathrm{K}_{2}=$ 0.95

4) cables are put in 2 layers, with a correction factor $\mathrm{K}_{3}=$ 0.8 ;

5) cables will be in tinned copper with type cross-linked polyethylene insulation.

The choice of the admissible current $I_{z}$ of the PV string cables must take into account not only the choice of the PV module protection device but also the various correction factors, in particular those due to the ambient temperature and to the laying method [11]. Thus, the admissible current $\left(I_{z}\right)$ is given by the following (11):

$$
I_{z} \geq 1,45 * \frac{I_{n}}{K_{1} * K_{2} * K_{3}}
$$

The value of $I_{n}$ is obtained from (6) or (7).

\subsubsection{Group Cables}

A group cable protection device against PV overcurrent is required only if the admissible current is less than the maximum reverse current group.

The group current $I_{s C_{-} S T C \text { group }}$ is given by (12) [11]:

$$
I_{S C_{-} S T C_{-} \text {group }}=\frac{N_{C}}{N_{a}} * I_{S C_{S T C}}
$$

With $\mathrm{N}_{\mathrm{a}}$ : number of generator groups, $\mathrm{N}_{\mathrm{c}}$ : the number of string in the group.

Equation (13) gives the current of the group protection devices:

$$
I_{n} \geq 1,25 * I_{S C \_S T C \_g r o u p}
$$

Then, the admissible current $\left(I_{z}\right)$ in a group of cable is given by (14), (15) and (16):

1) if the device is a fuse then:

$$
I_{z} \geq 1,45 \frac{I_{n}}{K_{1} * K_{2} * K_{3}}
$$

2) if the device is a circuit breaker then:

$$
I_{z} \geq 1,3 \frac{I_{n}}{K_{1} * K_{2} * K_{3}}
$$

3) without device then:

$$
I_{z} \geq 1,25 \frac{I_{S C_{S T C}} \text { group }}{K_{1} * K_{2} * K_{3}}
$$

\subsubsection{Alternating Current Cable}

The cables of the alternating current part are three phases and the inverter imposes the current so the supply current is $I_{M P P_{-} \text {inverter }}$. Taking into account the correction factors due to the temperature and the cable laying method, the permissible current is given by (17):

$$
I_{z} \geq \frac{I_{M P P_{\text {inverter }}}}{K_{1} * K_{2} * K_{3}}
$$


With I_MPP inverter: current of the maximum power point of the inverter and $\mathrm{K}_{1,2,3}$ are constants.

\section{Economic Analysis}

To perform the economic analysis, we determined the cost of the system per Wp. Indeed, PV system costs consist of module costs and costs of the so-called 'balance-of-system' (BOS), the latter representing all other system components, such as electrical installation, inverters, support structure and building integration grid connection or not [12]. Prices of PV modules and systems vary widely, depending on supplier, type, size and country. If one assumed a $\$ 3.00 / \mathrm{Wp}$ average 2003 price, experience curves would suggest prices might have fallen to $\$ 1.01 / \mathrm{Wp}$ by early 2012 . Historically, modules had a share of around $60 \%$ of the total PV system cost, but due to the extraordinary decline in module prices since 2008, its share in the total installed system cost has since decreased $[13,14]$. BOS components now represent the majority share of the total investment cost per watt and therefore represent one of the main potential sources of further cost reductions in photovoltaic systems. For the corresponding BOS for rooftop and ground-based PV systems, when it is connected to the grid, costs vary between approximately 1 to $4 \$ / \mathrm{Wp}$ [12]. In the light of these data, we assume the minimum cost of a grid photovoltaic installation estimated at $\$ 2.01 / \mathrm{Wp}$ or $1145.7^{1}$ $\mathrm{XOF} / \mathrm{Wp}$.

\section{Results and Discussion}

In order to have a reliable uninterruptible power source and while optimizing electricity consumption on the one hand, with regard to energy needs and on the other hand, we proposed to design a PV field with a power of $1 \mathrm{MWp}$ connected to the public grid. Power units are maintained to ensure continuity of services in the event of power failure of the grid. The diagram of the proposed system is shown in figure 9 .

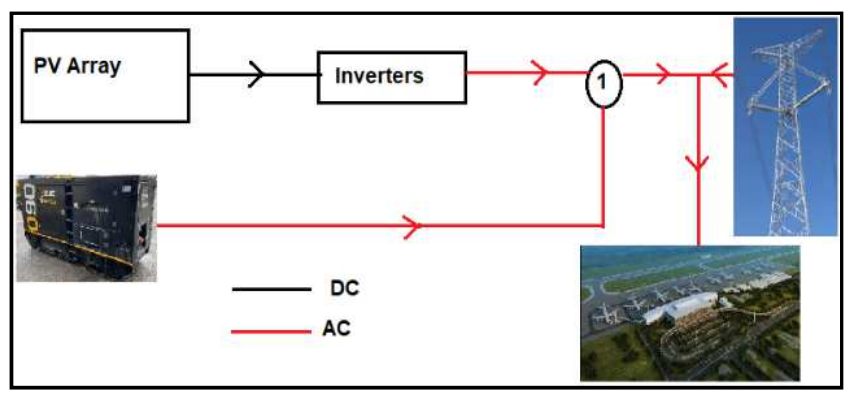

Figure 9. General overview of the photovoltaic plant diagram.

\subsection{Photovoltaic Generator}

The sizing results are presented in table 1 . The characteristics of the PV module and the inverter used are summarized in table 2.

$11 \$=570 \mathrm{fcfa}$ on the date of $08 / 06 / 2021$
Table 1. Results of the sizing of the PV power plant.

\begin{tabular}{ll}
\hline Installed Capacity & $1000 \mathrm{kWc}$ \\
$\mathrm{U}_{\text {mpp }}(\mathrm{STC})$ & $684 \mathrm{~V}$ \\
$\mathrm{I}_{\text {mpp }}(\mathrm{STC})$ & $1453 \mathrm{~A}$ \\
PV Field Orientation & $15^{\circ}$ \\
Number of PV modules & 2703 \\
Number of series module $\left(\mathrm{N}_{\mathrm{s}}\right)$ & 14 \\
Number of parallel modules by inverter $\left(\mathrm{N}_{\mathrm{c}}\right)$ & 12 \\
Number of inverter & 16 \\
Produced Energy $\left(E_{a}\right.$ en $M W h /$ year $)$ & 1503 \\
Module area $\left(\mathrm{m}^{2}\right)$ & 5245 \\
\hline
\end{tabular}

The system is composed of 2703 solar modules of $370 \mathrm{Wp}$ occupying a total area of $5245 \mathrm{~m}^{2}$ and 16 inverters. There are $16 \mathrm{PV}$ group, each having 12 strings. A string is composed of 14 modules. Each PV group is connected to an inverter. The configuration of a PV group is shown in figure 10.

Table 2. Characteristics of the PV module and the inverter used.

\begin{tabular}{llll}
\hline Module PV & \multicolumn{3}{c}{ Inverter } \\
\hline Module type & Si-mono & Operating mode & MPPT \\
\hline Model & JKM $370 \mathrm{M}-72$ & $\mathrm{U}_{\text {mpp_min }} / \mathrm{U}_{\text {mpp_max }}(\mathrm{DC})$ & $570 \mathrm{~V} / 800 \mathrm{~V}$ \\
$\mathrm{P}_{\mathrm{c}} / \mathrm{P}_{\text {mpp }}(\mathrm{Wc})$ & $370 / 370.3$ & $\mathrm{U}_{\min } / \mathrm{U}_{\max }(\mathrm{DC})$ & $565 \mathrm{~V} / 1000 \mathrm{~V}$ \\
$\mathrm{U}_{\mathrm{co}} / \mathrm{U}_{\mathrm{mpp}}(\mathrm{A})$ & $48.5 / 39.9$ & $\mathrm{P}_{\mathrm{n}} / \mathrm{P}_{\max }(\mathrm{DC})$ & $90 \mathrm{kWc}$ \\
$\mathrm{I}_{\mathrm{sc}} / \mathrm{I}_{\mathrm{mpp}}(\mathrm{A})$ & $9.61 / 9.28$ & $\mathrm{I}_{\text {nominale }} / \mathrm{I}_{\mathrm{sc}}(\mathrm{DC})$ & $110 \mathrm{~A} / 150 \mathrm{~A}$ \\
$\mathrm{Efficiency}$ & $19.2 \%$ & Efficiency & $98.8 \%$ \\
$\mathrm{I}_{\mathrm{RM}}$ & $20 \mathrm{~A}$ & Unit Nominal Power $(\mathrm{AC})$ & $60 \mathrm{~kW}$ \\
& & Operating Voltage & $400 \mathrm{~V}-480 \mathrm{~V}$ \\
& & $\mathrm{I}_{\max }(\mathrm{AC})$ & $87 \mathrm{~A}$ \\
\hline
\end{tabular}

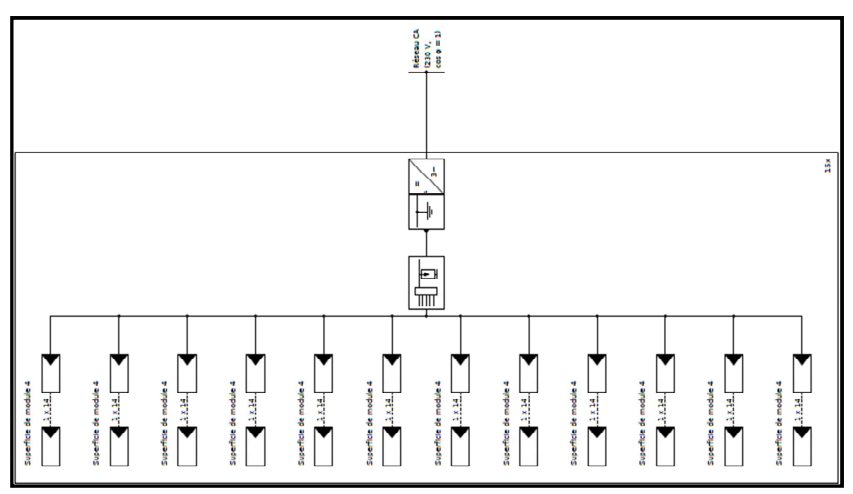

Figure 10. Configuration of the photovoltaic field.

\subsection{Solar Cables}

From equation (4), the maximum number of string in parallel without protection is $N_{c_{-} \max }=3$. However, according to the configuration, the number of string in parallel per inverter is equal to 12 ; then the use of devices protection against reverse currents is therefore to be expected. According to (6) and (8), the chosen protection device is a fuse with $16 \mathrm{~A}$ rating and a voltage of $1000 \mathrm{~V}$. The protection of photovoltaic installations against overvoltages of atmospheric origin is provided by DC surge arresters. The cable sizing results are summarized in table 3 : 
Table 3. Results cables sizing.

\begin{tabular}{lll}
\hline & Admissible current $\mathbf{( A )}$ & Section $\left(\mathbf{m m}^{\mathbf{2}}\right)$ \\
\hline String cable & 54 & 6 \\
PV group cable & 346 & 126 \\
AC cable & 213 & 70 \\
\hline
\end{tabular}

\subsection{System Performance}

Table 4 depicts the results of operating simulation. It reflects the monthly average energy injected into the grid in MWh. The maximum energy injected into the grid is in October with $140.7 \mathrm{MWh}$. Likewise, the minimum energy injected into the grid is in June with 102.5 MWh. The total active energy injected into the grid is $1502.7 \mathrm{MWh} /$ year with a performance ratio (PR) of 0.836 .

Table 4. Balance of the energy injected into the grid.

\begin{tabular}{llll}
\hline & EArray MWh & E_Grid MWh & PR \\
\hline January & 132.6 & 130.4 & 0.836 \\
February & 122.6 & 120.7 & 0.829 \\
March & 141.0 & 138.8 & 0.827 \\
April & 132.5 & 130.4 & 0.830 \\
May & 125.7 & 123.6 & 0.830 \\
June & 104.3 & 102.5 & 0.846 \\
July & 110.1 & 108.2 & 0.846 \\
August & 113.8 & 111.9 & 0.847 \\
September & 127.9 & 125.8 & 0.839 \\
October & 143.0 & 140.7 & 0.836 \\
November & 140.5 & 138.2 & 0.830 \\
December & 133.6 & 131.4 & 0.835 \\
Year & 1527.7 & 1502.7 & 0.836 \\
\hline
\end{tabular}

Figure 11 shows the detailed annually average system losses. The loss due to the temperature of the field is 18479 Kwh/year. The energy of the virtual field at MPP is $1,528,000 \mathrm{kWh} /$ year.

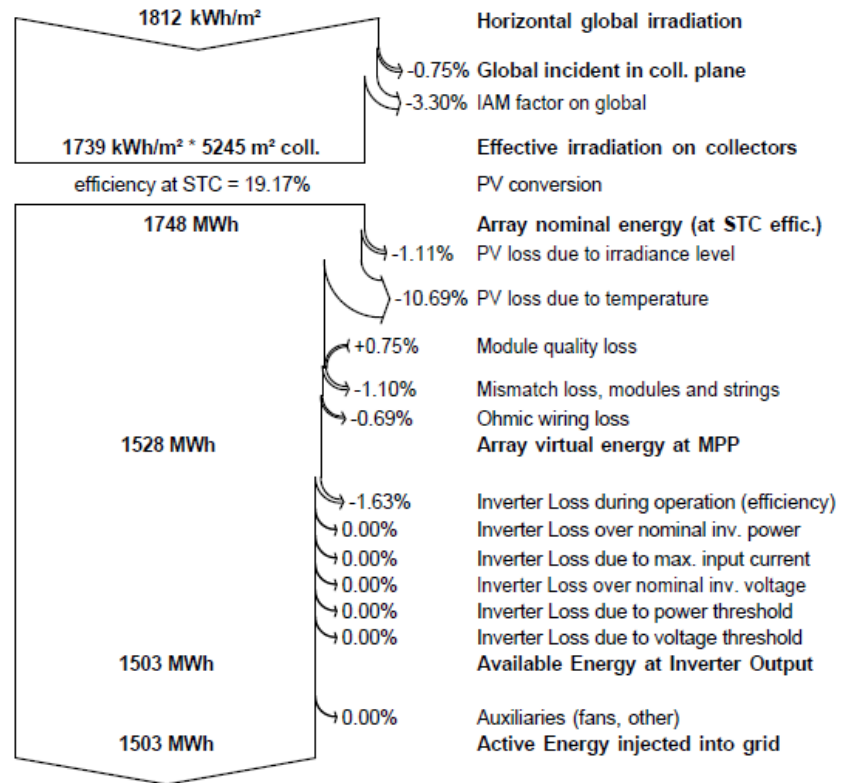

Figure 11. Energy losses diagram over the whole year.

\subsection{Economic and Environmental Profitability Analysis}

Referring to the capacity of the PV field and the Wp cost, the cost of the project is estimated at $1,145,700,000 \mathrm{XOF}$ or $\$ 2,010,000$.

\subsubsection{Comparative Economic Study}

A comparative study is carried out between the proposed grid-connected PV system and the current power supply from the grid. The results of this study are presented in table 4 . The chosen comparison criteria is the annual cost of electricity bill before the installation of the PV plant and after it. The average purchase price including tax per $\mathrm{kWh}$ from the electricity company is estimated at 110 XOF or $\$ 0.19$.

Table 5. PV plant profitability simulation.

\begin{tabular}{lll}
\hline & Without PV & With PV \\
\hline $\begin{array}{l}\text { Annual power consumption from the grid } \\
\text { (MWh) }\end{array}$ & 6745,57 & 5242,87 \\
$\begin{array}{l}\text { Annual cost of the electricity bill (USD) } \\
\text { Annual savings on the electricity bill }\end{array}$ & $1,301,776.67$ & $1,011,781.93$ \\
(USD) & 0 & $289,994.74$ \\
\hline
\end{tabular}

From Table 5, it can be seen that the grid-connected PV power plant solution is economically more profitable than suppling electricity from the public grid alone. The use of photovoltaic solar grid-connected through 16 inverters will make it possible to cover more than $18 \%$ of energy needs, this will make a projected gain of $1502.7 \mathrm{MWh} /$ year, i.e. a saving of $165,297,000$ XOF or $\$ 289,994.74 /$ year.

\subsubsection{Economic Profitability Analysis}

In the study of a PV system, it is important to have an idea of the profitability of the project, this by determining the cost of $\mathrm{kWp}$. This cost will be lower than the price per $\mathrm{kWh}$ of the grid electricity if the photovoltaic production is selfconsumed. To calculate this cost, we took into account operating and maintenance costs, insurance costs, operating fees, financial borrowing rate, etc. In order to evaluate the time of profitability, the study of profitability covers two cases, namely: bank loan or own funds.

In the first case, we assume a bank loan of $60 \%$ of the plant's investment cost (or $\$ 1,206,000$ ) with a refundable interest rate of $6 \%$ in 10 years. The operating costs of the plant, made up of maintenance costs, upkeep and insurance costs, loan rate, are given by (18) [12]:

$$
C_{\text {ann }}=I *\left(r_{O \& M}+\frac{0.6 * t_{i n t}}{1-\left(1+t_{\text {int }}\right)^{-n}}+A s s\right)+R d v
$$

With: $I$, investment cost; $r_{O \& M}$ : annual cost of operation and maintenance (as a percentage of $\mathrm{I}$ ); $\mathrm{t}_{\mathrm{int}}$ : loan rate; $n$ : refundable period, Ass: insurance rate and operating fee and $R d v$ : royalty.

We suppose: $r_{O \& M}=3 \% t_{\text {int }}=6 \%, \mathrm{n}=10$, Ass $=0.1 \%$ and $\mathrm{Rdv}=500000 \mathrm{XOF}$ or $\$ 877.19$.

The profitability rate is $1.28 \%$. The evaluation of the cumulative cash flow shows that the project will be profitable from the 16th year of the life of the system as shown in figure 12 . The cost price of the KWp thus obtained is 86.11 


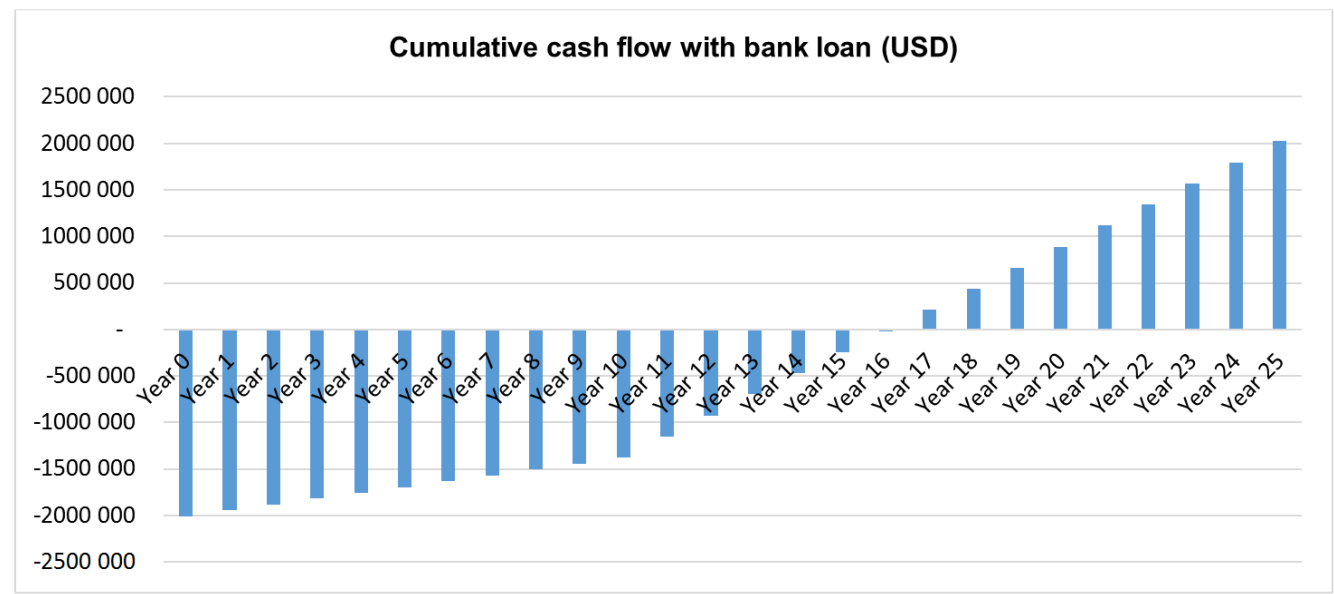

Figure 12. Cumulative cash flow with bank loan.

In the event that the project is financed with own funds, the operating costs of the plant are given by (19) [12]:

$$
C_{\text {ann }}=I *\left(r_{O \& M}+A s s\right)+R d v
$$

We suppose: $r_{O \& M}=3 \%$, Ass $=0.1 \%$ and $\mathrm{Rdv}=500000$ XOF or $\$ 877.19$.
The profitability rate is $4.59 \%$. The evaluation of the cumulative cash flow shows that the project will be profitable from the $9^{\text {th }}$ year of the life of the system as shown in figure 13. The cost price of the KWp obtained is $23.96 \mathrm{XOF} / \mathrm{KWp}$ or $\$ 0.04 / \mathrm{KWp}$ also much lower than the average price per $\mathrm{kWh}$ of the grid.

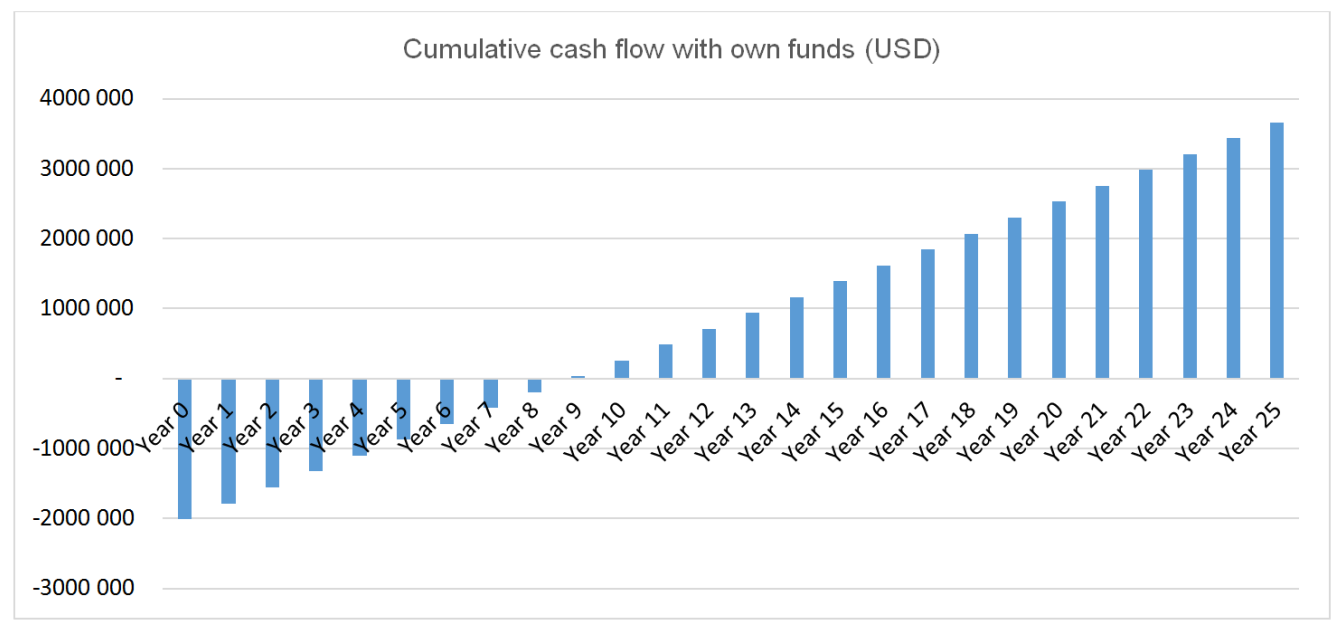

Figure 13. Cumulative cash flow with own funds.

\subsection{Environmental Impact}

Any renewable energy project contributes to the reduction of greenhouse gas (GHG) emissions, mainly $\mathrm{CO}_{2}$. In the context of this project to install a photovoltaic solar power plant at the airport, the challenges are high. The objective is to determine the $\mathrm{CO}_{2}$ emissions avoided following the completion of this project. The assessment is made according to equation (20) [14]:

$$
\text { Emissions }_{G H G}=\text { Energy }_{\text {produced }} * F E_{G H G}
$$

$F E_{G E S}$ : GHG emission factor, expressing the amount of $\mathrm{CO}_{2}$ avoided per KWh of electricity produced. Energy $y_{\text {produced }}$ : energy produced by the photovoltaic plant $\left(\mathrm{E}_{\mathrm{a}}\right)$.
For energy production, $\mathrm{GHG}$ emission factor is $267 \mathrm{~g} \mathrm{CO}_{2}$ / KWh in Togo [14]. In our case, the photovoltaic plant would help to avoid 401.3 tonnes of $\mathrm{CO}_{2}$ per year.

\section{Conclusion}

In this study, a self-consumption grid-connected PV system located on the site of the AIGE, has been sized and simulated in PVsyst software to evaluate energy performance. The results show that the system is composed of 2703 solar panels of $370 \mathrm{~W}$ and 16 inverters of $90 \mathrm{KW}$. The energy production injected into the grid is 1,502.7 $\mathrm{MW} /$ year with a performance ratio of $83.6 \%$. This shows that the airport of Lomé has great potential for the use of solar energy due to its strategic location. The investment cost of 
the project is estimated at $1,145,700,000 \mathrm{XOF}$ or $\$ 2,100,000$. The profitability analysis is carried out depending on the case where the project is financed with own funds or by a bank loan. It appears that the profitability rate is $4.59 \%$ for own funds and the project will be profitable from the $9^{\text {th }}$ year of the system's life. For bank loan of $60 \%$ of the plant's investment cost, the project will be profitable from the $16^{\text {th }}$ year. Besides, the project plant would help to avoid 401.3 tonnes of $\mathrm{CO}_{2}$ per year.

The photovoltaic system is therefore establishing itself as the technical and economical solution for supplying electricity to airports where the solar potential is very great.

\section{Acknowledgements}

The authors would like to thank the respective responsible leaders of the international airport GNASSINGBE Eyadéma and of national meteorology for the internship and the climate data sharing. The usual disclaimer applies.

\section{References}

[1] https://www.universalis.fr/encyclopedie/carburants-pourlaviation/2-aeronautique-emissions-et-environnement /[Online] [Cited: 11 25, 2020.].

[2] Boudet, Antoine. LesEchos. [Online] 12 02, 2018. [Cited: 06 25, 2020.] https://www.lesechos.fr/industrieservices/tourisme-transport/les-aeroports-cherchent-aameliorer-leur-bilan-carbone-187392.

[3] Organization International Civil aviation. Airport Planning Manual Part II - Land Use and Environmental management. Montréal: s.n., 4e, 2018.

[4] https://www.latribune.fr/entreprises-finance/services/transport logistique/20140702trib000838116/avec-quelle-energiefonctionne-un-aeroport-.html.

[5] Batamag, Emmanuel. [Online] 01 15, 2019. [Cited: 02 16, 2020.] https://www.afrik.com/cameroun-1-aeroportinternational-de-douala-beneficie-desormais-d-installation-depanneaux-solaires-photovoltaiques.
[6] Komi Apélété AMOU, Tchamye Tcha-Esso BOROZE, Sanoussi OURO-DJOBO, Koffi SAGNA, Yaovi Ouézou AZOUMA, Magolmèèna BANNA, and Kossi NAPO An application of the Multilayer Perceptron: Estimation of Global Solar Radiation and the Establishment of Solar Radiation Maps of Togo. 1, 2017, Sustainable Energy, Vol. 5, pp. 6-15.

[7] S. Bouacha, A. Hadj Arab, N. Belhaouas, S. Semaoui, M. Haddadi. Modeling and simulation of $1 M W$ Grid Connected Photovoltaic System. 0042, 2015, The 2nd International Conference on Power Electronics and their Applications.

[8] K. Kety, K. A. Amou, K. Sagna, K. Tepe, Y. Lare et K. Napo. Modélisation et simulation d'un générateur photovoltaïque: Cas du module polycristallin Ecoline LX-260P installé au dispensaire de Sévagan (Togo). 4, 2016, Revue des Energies Renouvelables, Vol. 19, pp. 633 - 645.

[9] Johann Hernandez, Nelson L. Diaz. Design-Dimensioning Model For Grid-Connected Photovoltaic Systems. 2009. IEEE Electrical Power \& Energy Conference.

[10] S. B. Kjaer, J. K. Pedersen and F. Blaabjerg. A Review of Single-Phase grid-Connected Inverters for Photovoltaic Modules, 5, 2005, IEEE TRANSACTIONS ON INDUSTRY APPLICATIONS, Vol. 41.

[11] (UTE), Union Technique de l'Electricité. Guide pratique: Installations photovoltaïques raccordées au réseau public de distribution. 2010.

[12] Zwaan, Bobvan der and Rablc, Ari. The learning potential of photovoltaics: implications for energy policy. 2004, Energy Policy, Vol. 32, pp. 1545-1554.

[13] Morgan Bazilian, Ijeoma Onyeji, Michael Liebreich, Ian MacGill, Jennifer Chase, Jigar Shah, Dolf Gielen, Doug Arent, Doug Landfear, Shi Zhengrong Re-considering the economics of photovoltaic power, 2013, Renewable Energy, Vol. 53, pp. 329-338.

[14] Edward S. Rubin, Inès M. L. Azevedo, Paulina Jaramillo, Sonia Yeh, "A review of learning rates for electricity supply technologies", Energy Policy, Volume 86, 2015, Pages 198-218, ISSN 0301-4215, https://doi.org/10.1016/j.enpol.2015.06.011. (https://www.sciencedirect.com/science/article/pii/S03014215150 02293).

[15] République Togolaire, Rapport national d'inventaire de GES. Septembre 2017. 